\title{
Microstructure and Properties of the Copper Alloyed with Ag and Ti Powders Using Fiber Laser
}

\author{
Mariusz Krupiński *(D), Paulina Ewelina Smolarczyk $(\mathbb{D}$ and Mirosław Bonek (1) \\ Department of Engineering Materials and Biomaterials, Silesian University of Technology, Konarskiego 18a, \\ 44-100 Gliwice, Poland; paulina.smolarczyk@polsl.pl (P.E.S.); miroslaw.bonek@polsl.pl (M.B.) \\ * Correspondence: mariusz.krupinski@polsl.pl
}

Received: 28 April 2020; Accepted: 24 May 2020; Published: 26 May 2020

\begin{abstract}
The scope of the work covers the development of the relationship between the chemical composition of surface-modified copper and the diffusion of alloy elements as well as the microstructure and mechanical properties. This article presents the impact of laser alloying with titanium and silver powders on the microstructure and mechanical properties of copper. In order to investigate the phenomena occurring during the laser alloying process, microstructural studies were performed using scanning electron microscopy (SEM), optical microscopy, and energy dispersive $\mathrm{x}$-ray spectroscopic (EDS) analysis of the chemical composition in micro-areas. In addition, to test the properties of the resulting alloy, abrasion resistance, hardness measurement at low loading force, and conductivity measurements were performed. As a result of alloying with Ag and Ti powders, three distinct zones were indeed recognized: re-melting zone (RZ), diffusion zone (DZ), and heat affected zone (HAZ). The surface modification that results from laser alloying increases the hardness as well as the abrasion resistance of the material. Overall, it was found that laser alloying with Ti powder increased the strength of the copper surface layer due to the formation of intermetallic phases $\left(\mathrm{Cu}_{3} \mathrm{Ti}_{2}\right)$. It was also found that laser alloying with $\mathrm{Ag}$ powder changed the mechanical properties of the surface layer due to the solid solution strengthening.
\end{abstract}

Keywords: non-ferrous metal; copper; alloying; laser surface modification; microstructure

\section{Introduction}

It is well-known that copper has good conductivity properties, although it lacks significant strength. Strengthening of copper is most often obtained by plastic deformation, however, this method has a disadvantage in the fact that at elevated temperatures, recrystallization occurs, which decreases strengthening. Other methods require chemical composition modification and concern the strengthening of copper alloys and include dispersion, precipitation, solid solution strengthening, or strengthening through intermetallic phases [1-3].

There are various other methods to improve the mechanical properties of copper such as alloying. Research aimed at improving the material structural quality, while maintaining an electrical conductivity above $57 \mathrm{MS} / \mathrm{m}$ has been carried out. For example, CuB2 and CuZr30 grain refinements have been used to modify certain materials. The test results showed that the modification of the chemical composition caused grain refinement and also maintained the electrical conductivity [4]. Copper alloys such as $\mathrm{Cu}-\mathrm{Ni}-\mathrm{Si}$ and $\mathrm{Cu}-\mathrm{Cr}$, modified with rhenium and silver to improve mechanical properties, have also been investigated and it was discovered that supersaturated, plastically deformed, and aged alloys showed increased mechanical properties in these types of alloys $[5,6]$.

It is also possible to use plastic deformation to change the mechanical properties of copper. Specifically, increased abrasion resistance is obtained following large-scale copper plastic deformation. In general, coarse-grained copper has been shown to have better abrasion resistance [7], however, 
there was no significant increase in electroconductivity at the obtained grain refinement compared to the coarse-grained structure.

Grain refinement due to plastic deformation may be reduced in recrystallization, and copper is often employed at elevated temperatures that promote such recrystallization processes. During copper modification, the side effect of increasing mechanical properties is a decrease in conductivity [8]. It is important that in the main copper supply, the current flows entirely on the surface of the cable (i.e., the so-called skin effect in electrical engineering). Considering that a copper surface is prone to oxidation, this resistance may be much higher than that resulting from the conductivity value of the pure bulk metal [8,9].

Modification of the chemical composition with alloying elements can be particularly helpful when altering the surface layer. It allows for adapting mechanisms that occur in the alloy for use in surface modifications, although, as a rule, cooling speeds in the latter processes are much faster. In $[10,11]$, it was found that the occurrence of $\mathrm{Ag}$ phases as well as $\mathrm{CuTi}_{2}, \mathrm{Cu}_{3} \mathrm{Ti}_{2}$, and $\mathrm{Cu}_{4} \mathrm{Ti}_{3}$ are possible. As soon as the eutectic $\mathrm{Ag}-\mathrm{Cu}$ alloy melts (melting point (M.P.) $=780^{\circ} \mathrm{C}$ ), the Ti begins to dissolve in the liquid. When the Ti activity in the liquid is sufficiently high near the Ti surface, the $\mathrm{Cu}_{4} \mathrm{Ti}$ compound nucleates and rapidly forms a continuous reaction layer of small crystals that extracts Ti from the liquid. Other Ti-Cu compounds can then nucleate and grow via solid-state reaction-diffusion between Ti and the $\mathrm{Cu}_{4}$ Ti layer. A reaction zone is thus formed (Figure 1a), consisting of four dense, single-phased layers of compounds arranged according to the diffusion path (Figure $1 \mathrm{~b}$ ) in the $\mathrm{Cu}-\mathrm{Ag}$-Ti phase diagram (see Figure 2) [12,13].

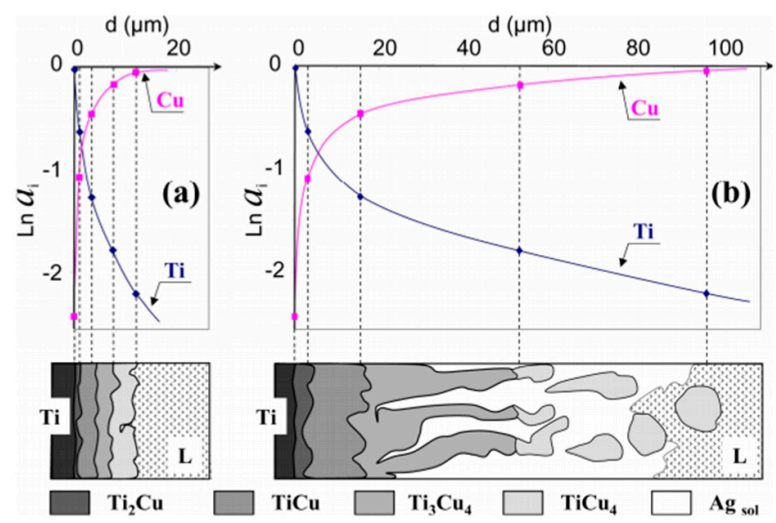

Figure 1. (a) Chemical activity of $\mathrm{Cu}$ and $\mathrm{Ti}$ in intermetallic phases formed as a result of the reaction at $790{ }^{\circ} \mathrm{C}$ in pure and (b) saturated $40 \% \mathrm{Ti}-\mathrm{Ag}$ in a liquid $\mathrm{Cu}$ alloy Reprinted with the permission of [12].

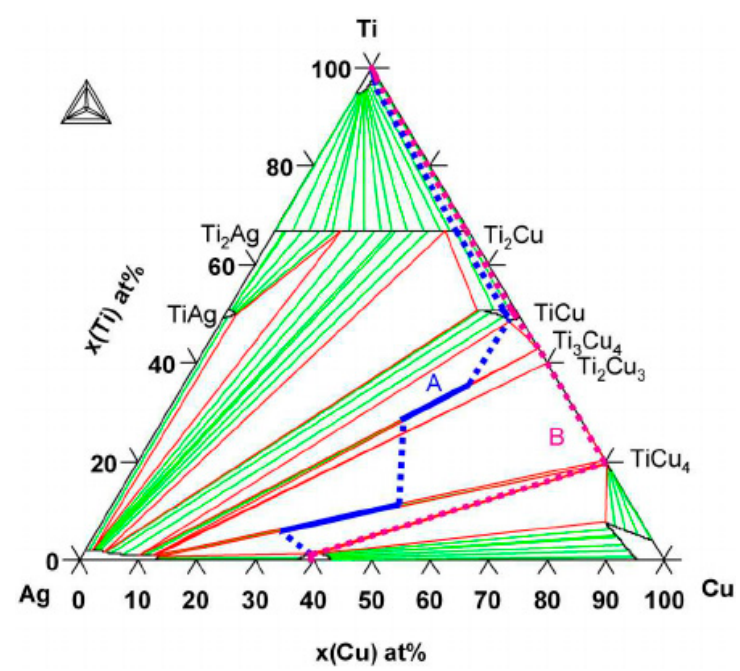

Figure 2. The $\mathrm{Cu}-\mathrm{Ag}-\mathrm{Ti}$ ternary phase diagram calculated at $790{ }^{\circ} \mathrm{C}$. Two diffusion paths have been drawn corresponding to the reaction zones Reprinted with the permission of [12]. 
The modification of the surface layer of metals and alloys with a laser beam is used in a number of surface treatments such as alloying, melting, and re-melting. In the cases of alloying, feathering, and melting, it is also possible to change the chemical composition of the created layer. Various other effects including homogenization, grain refinement, and increased hardness of the surface layer are usually obtained as a result of re-melting. Re-melting treatments generally induce a tensile stress that is associated with the heating and cooling processes of the improved layer $[14,15]$. The stress value depends on the parameters of the laser treatment (i.e., the radiation power density); the method of laser processing, whether it is a single transition or multi-path treatment; the degree of covering the paths; the type of material; any phase changes occurring during the heat treatment; and finally, the adopted measuring method [16-18].

During laser surface modification of metals and their alloys, various types of lasers can be used. For example, Nd: YAG (neodymium-doped yttrium aluminum garnet) lasers ( $\lambda=1064 \mathrm{~nm}, 2.5 \mathrm{~kW})$ are employed to increase corrosion and abrasion resistance [19], and they can be applied at lower laser power $(\lambda=1064 \mathrm{~nm}, 2 \mathrm{~kW})$ to reduce hardening costs in low-alloy steels [20]. $\mathrm{A} \mathrm{CO}_{2}$ laser $(10 \mathrm{~kW})$ is used for grain refinement, or to increase corrosion resistance or change the microstructure [21]. It was reported that a $\mathrm{CO}_{2}$ laser could be used for alloying with $\mathrm{TiO}_{2}$ and $\mathrm{SiC}$ powders to modify the microstructure and microhardness of aluminum [22]. Fiber lasers $(\lambda=1064 \mathrm{~nm}, 2 \mathrm{~kW})$ are used to increase wear resistance and corrosion resistance [23], and interestingly, lasers of this type with increased power $(8 \mathrm{~kW})$ are used in the process of laser metal deposition [24]. Fiber lasers with a power of $4 \mathrm{~kW}$ and a wavelength of $\lambda=1070 \mathrm{~nm}$ have been used to increase the wear resistance and hardness of aluminum alloys as a result of microstructural changes [25].

Laser modification has also been shown to improve the strength of a $\mathrm{Cu}$ surface layer. In these experiments, a Ni-based powder was applied to a copper surface using an acetone solution of cellulose acetate as a binder. It was found that after modification, the sample hardness increased by a factor of six, and the electrical conductivity decreased slightly. The increase in mechanical properties has been attributed to the precipitation hardening of boride and carbide [26]. Laser surface treatment also has applications toward increasing the abrasive wear resistance of the treated material. Depending on the material used, a fine, more homogeneous structure can be obtained, which consequently leads to increased wear resistance [27].

Modification of copper for industrial applications is largely focused on increasing wear resistance, which contributes to increasing the service life of copper electrical contacts [28]. In laser beam processes, the selection of system parameters is very important (e.g., if the laser beam power density is too low or the scanning speed is too high, the structure of the resulting melted layer may be heterogeneous) [29].

Laser surface modification is a common technique that is used mainly with oxides and carbides. The use of ceramic powders has many advantages including structural stability, even at elevated temperatures. The disadvantages of this method include (i) wettability, (ii) conglomerate formation, (iii) the large amount of powder that must be introduced into the melted zone, (iv) the powder's morphology and size, and (v) the melting and subcooling of powders (mainly carbon component) into solution. The use of pure metals may cause strengthening as a result of the formation of intermetallic phases, precipitation, and solid solution mechanisms. A material with high mechanical properties including creep resistance, and high conductivity of the surface layer can be applied in contact-friction joints, commutators, sliding contacts, or electrode tips, which was the reason for using Ag and Ti to modify the laser surface of copper.

\section{Materials and Methods}

In order to investigate the effect of the laser modification of the copper surface layer with $\mathrm{Ti}$ and $\mathrm{Ag}$ powders on its microstructure and properties, the following steps were undertaken:

- $\quad 99.95 \%$ pure, drawn flat copper bar (M1Ez4) delivered by the Kafra Color Metals Company (Warsaw, Poland) was used. Dimensions: length $=80 \mathrm{~mm}$; width $=30 \mathrm{~mm}$; thickness $=10 \mathrm{~mm}$. Samples were ground with sandpaper \#1200. 
- Titanium powder (purity 99.5\%, -325 mesh) and silver powder (purity 99.9\%, -325 mesh) delivered by Alfa Aesar (Kandel, Germany) were applied to the surface of the copper.

- Alloying of the surface layer was performed with the fiber laser, Ytterbium Laser System, YLS-4000-S2T (IPG Photonics Corporation, Oxford, MA, USA; $\lambda=1070 \mathrm{~nm}$, maximum laser beam power $=4000 \mathrm{~W}$ ). Various process parameters were tested, but the best results were achieved for the parameters given in Table 1. Helium was the protective gas during the process. Twenty samples with were performed with a laser. The re-melting width was $2-3 \mathrm{~mm}$ and length was $38-42 \mathrm{~mm}$ (Figure 3).

- Zeiss Supra 35 scanning microscope (SEM, Thornwood, New York, NY, USA) was used to study the microstructure using the secondary electron method. The EDS technique (energy-dispersive $x$-ray spectroscopy) was used for the quantitative and qualitative analysis of micro-areas. Directly before the process, the treated surface was mechanically ground $(15 \mathrm{~mm})$ and cleaned with methyl alcohol and compressed air.

- Metallographic analysis was performed using optical microscopy on an Axio Observer from Zeiss (Thornwood, New York, NY, USA). After grinding, the laser-alloyed copper was subjected to polishing and electrolytic etching in D2 Struers Electrolyte (Thornwood, New York, NY, USA) (polishing: time $=10 \mathrm{~s}$, voltage $=10 \mathrm{~V}$; etching: time $=3 \mathrm{~s}$, voltage $=2 \mathrm{~V}$; temperature $=24^{\circ} \mathrm{C}$ ) on a Struers LectroPol-5 device (Thornwood, New York, NY, USA). Observations were made in bright field and in polarized light.

- $\quad$ Tests were carried out using a copper cathode (wavelength $=1.5406 \AA$ A) on a Panalytical MPD $X^{\prime}$ Pert Pro device (Egham, UK), enabling the determination of the interplanar distance and phase composition after modification.

- Vickers hardness method [HV1] was measured on a Future Tech FM-ARS 900 device (FM-ARS9000, Future-Tech, Tokyo, Japan); process parameters: $t=12 \mathrm{~s}, \mathrm{~F}=9807 \mathrm{~N}$. Five hardness measurements were taken for each sample. Measurements were made on the copper surface along each alloying.

- Conductivity tests were performed on a Sigmatest Foerster 2.069 (FOERSTER, Pittsburgh, PA, USA) device, which measures the electrical conductivity based on the complex impedance of the probe. Measurements were carried out at ambient temperature with a device operating frequency of $60 \mathrm{kHz}$. Before measuring the samples, the device was calibrated on a set of two standards with electrical conductivity values of $4.4 \mathrm{MS} / \mathrm{m}$ ( $8 \%$ IACS) and $58 \mathrm{MS} / \mathrm{m}$ (100\% IACS). Samples were ground with sandpaper with a grain size of $3 \mu \mathrm{m}$.

- Abrasion resistance was tested on the Tribometer CSM Instruments device by the ball-on-plate method using a ceramic ball $\left(\mathrm{Al}_{2} \mathrm{O}_{3}\right)$ with a $6 \mathrm{~mm}$ diameter as a counter-sample; dry test environment at ambient temperature. Parameters: full amplitude $=6 \mathrm{~mm}$, linear speed $=2 \mathrm{~cm} / \mathrm{s}$, counter-sample load $=5 \mathrm{~N}$, sliding distance $=25 \mathrm{~m}$, frequency $=1.06 \mathrm{~Hz}$. Reciprocating linear motion. Samples were ground with sandpaper with grain size \#2400.

- Using the Taylor-Hobson Surtronic 25 contact profilometer (Taylor Hobson Ltd., Leicester, UK), the wear track profile was tested with the following parameters: sampling line $=1.25 \mathrm{~mm}$, wipe path $=6 \mathrm{~mm}$. Resolution at $10 \mu \mathrm{m}$ range $-0.01 \mu \mathrm{m}$, resolution at $100 \mu \mathrm{m}$ range $-0.1 \mu \mathrm{m}$. Based on the wear profile field and the length of wear tracks, the volume of worn material was determined.

Table 1. Process parameters.

\begin{tabular}{cccccc}
\hline Power, kW & Laser Beam Diameter, $\mathbf{m m}$ & Scan Number & Scan Speed, $\mathbf{m} / \mathbf{m i n}$ & Gas, L/min & Powder \\
\hline $3-4$ & 3 & $1-3$ & 0.06 & Helium, 2 & $\frac{\text { Silver }}{\text { Titanium }}$ \\
\hline
\end{tabular}



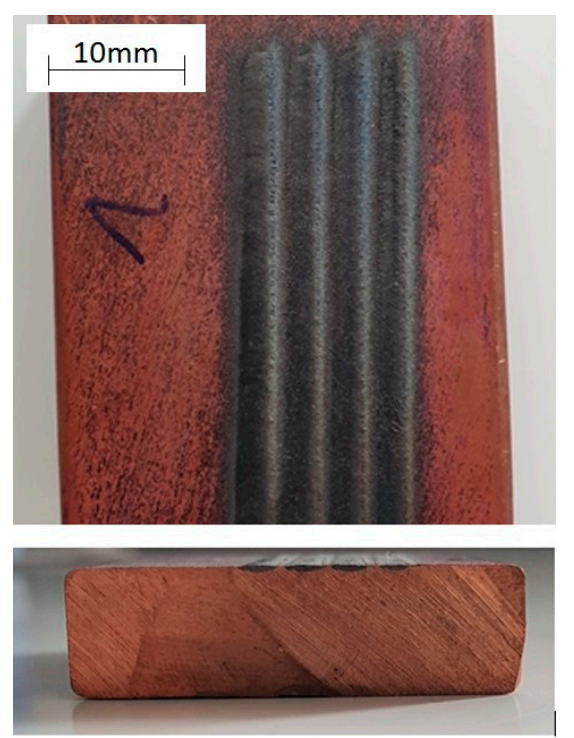

Figure 3. Sample of the melting's surface and a cross-section before grinding with sandpaper.

\section{Results and Discussion}

Modification of a copper surface with silver powders using laser techniques resulted in the segregation of three zones, namely, the re-melting zone (RZ), the diffusion zone (DZ), and the heat affected zone (HAZ), as shown in Figure 4. As in the Ag case, titanium powder alloying also resulted in the creation of similar zones (Figure 5). The re-melting zones were measured to be $392.67 \mu \mathrm{m}$ for copper alloyed with silver powder, and $439.7 \mu \mathrm{m}$ for titanium alloyed copper.

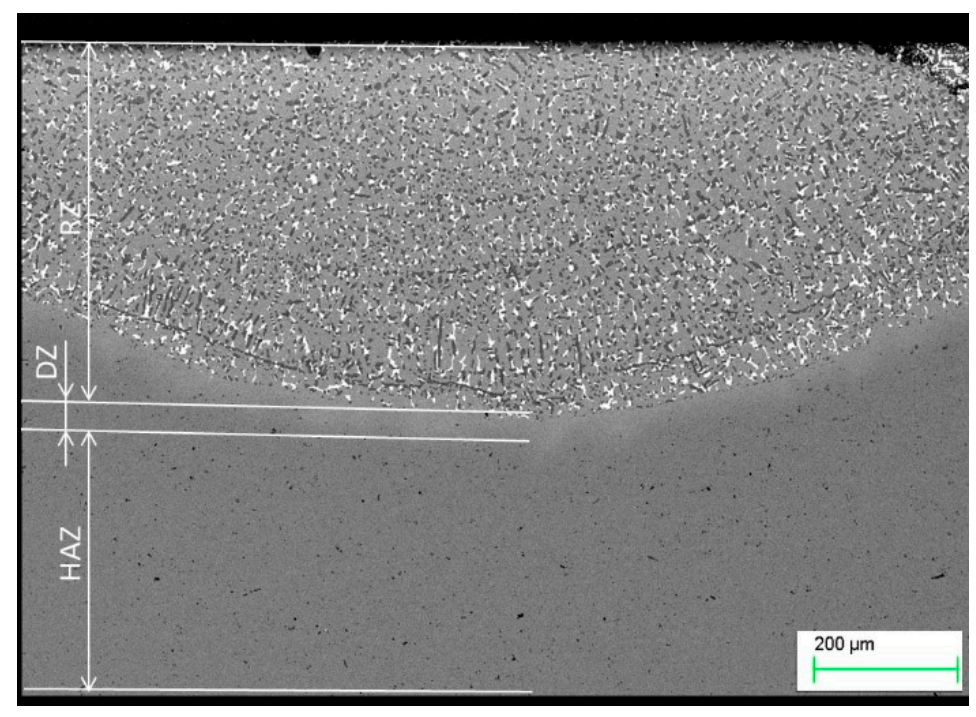

Figure 4. Microstructure of copper after Ag alloying. $R Z=$ re-melted zone, $D Z=$ diffusion zone, $\mathrm{HAZ}=$ heat affected zone.

Depending on the powders used and the heat dissipation rate, different processes occur in the visible re-melting zone. In the solidified zone, part of the silver was dissolved in the $\alpha$ matrix, while, due to segregation, its excess was released in the form of $\mathrm{Cu}+\mathrm{Ag}$ globular eutectics, which can be seen in Figure 6. The EDS analysis of the micro-areas marked in Figure $6 a$, is shown in Figure $6 b-d$ (Table 2). Some of the silver (about $9 \mathrm{wt} . \%$ ) was dissolved in the $\alpha$ matrix (Figure 6a) as a result of the solidification of the re-melted zone (RZ) (Figure 4), and because of the mass of the samples, the cooling rate was large enough that the excess silver remained dissolved in the matrix. When the excess silver was pushed out by the crystallization front, this led to the micro-segregation and coagulation of 
$\mathrm{Cu}+$ Ag eutectic at the $\alpha$ phase boundary (interdendritic spaces). The size of the remaining eutectics was between $2-3 \mu \mathrm{m}$ in diameter. Therefore, due to this alloying, the mechanical properties of the material including hardness were increased.

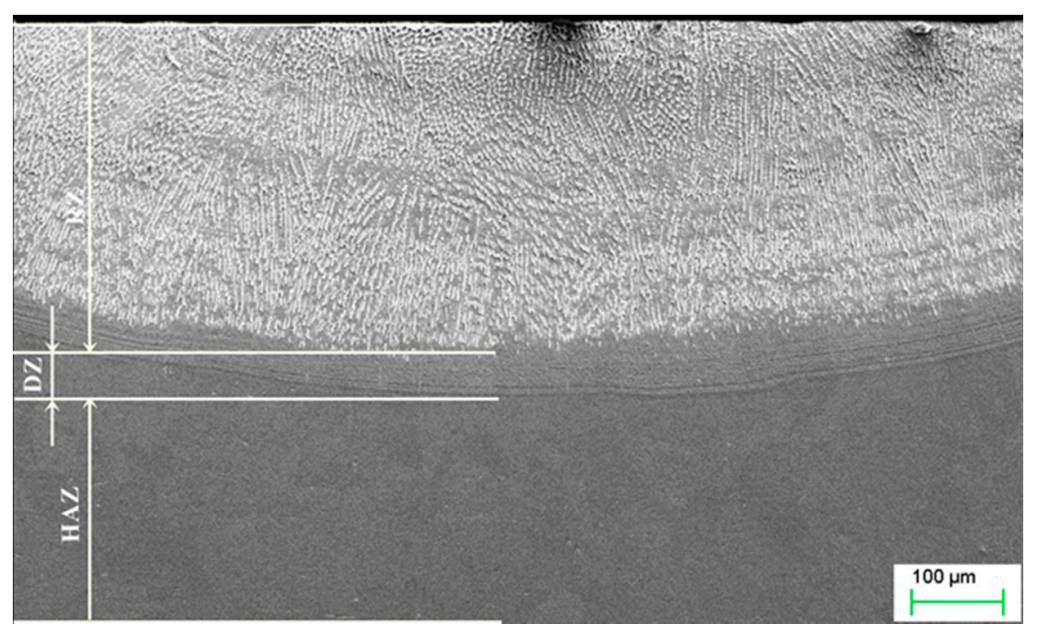

Figure 5. Microstructure of copper after Ti alloying. $R Z=$ re melted zone, $D Z=$ diffusion zone, $\mathrm{HAZ}=$ heat affected zone.

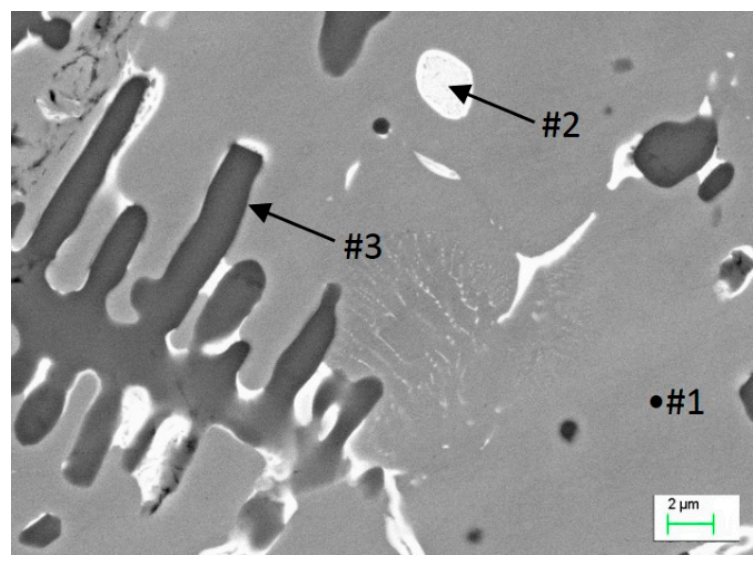

(a)

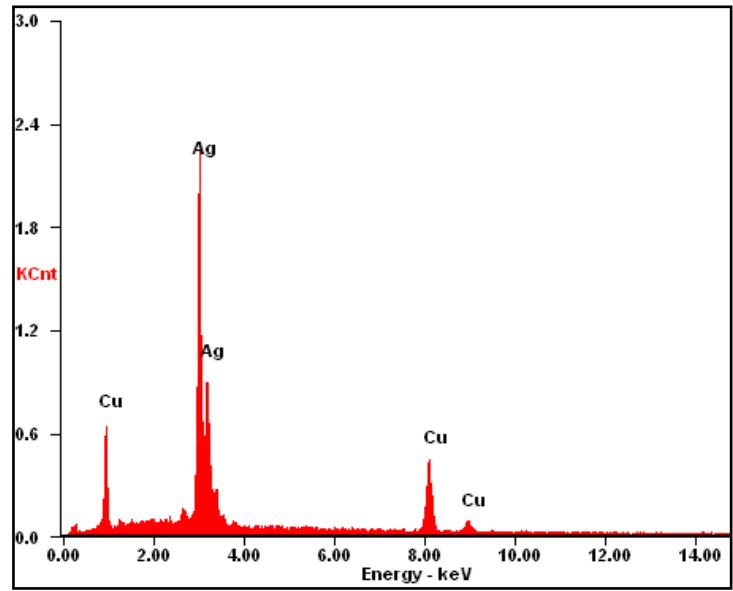

(c)

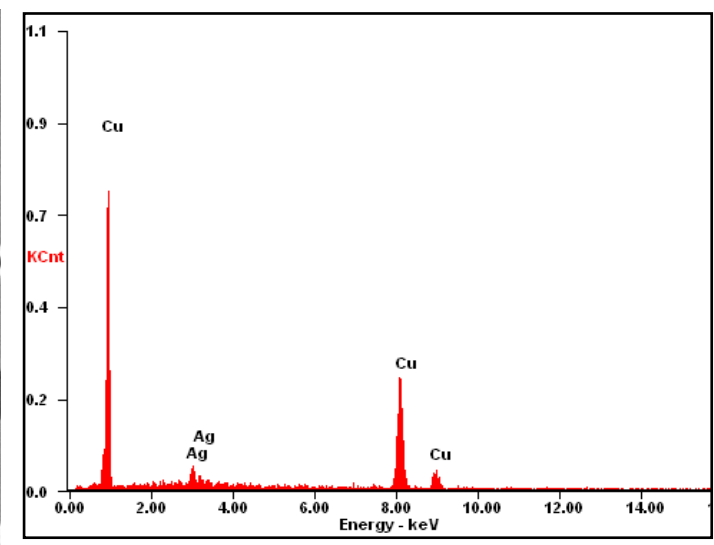

(b)

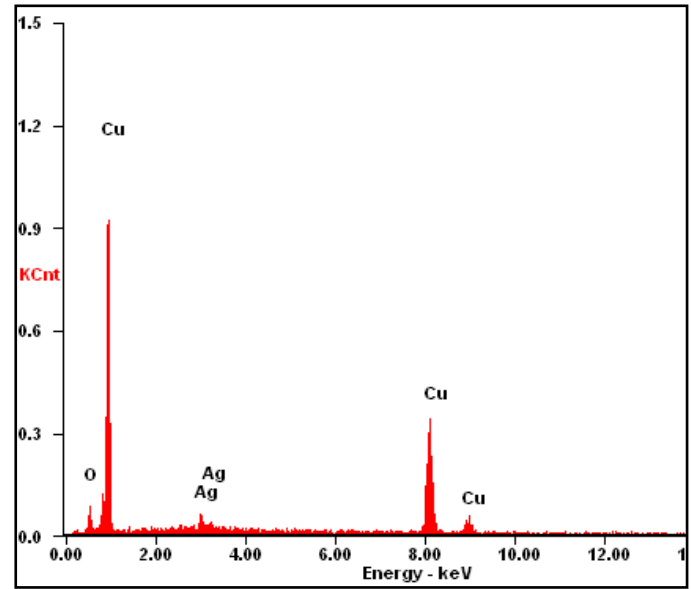

(d)

Figure 6. (a) Microstructure of $\mathrm{Cu}$ after alloying by $\mathrm{Ag}$ : \#2 $\mathrm{Cu}+\mathrm{Ag}$ eutectic; (b) analysis of energy dispersive $\mathrm{x}$-ray spectroscopy (EDS) from the micro-area \#1; (c) analysis of EDS from the micro-area \#2; and (d) analysis of EDS from the micro-area \#3. 
Table 2. Results of the EDS spectrum analysis for the areas from Figure 6 (wt.\%).

\begin{tabular}{cccc}
\hline Element & Point \#1 (Figure 6a) & Point \#2 (Figure 6a) & Point \#3 (Figure 6a) \\
\hline $\mathrm{Cu}$ & 92.11 & 31.61 & 87.32 \\
$\mathrm{Ag}$ & 7.89 & 68.39 & 5.55 \\
$\mathrm{O}$ & - & - & 7.13 \\
\hline
\end{tabular}

The re-melting zone of the copper alloyed with titanium powder showed directional solidification (toward the front of heat dissipation) as shown in Figures 7 and 8. In the case of solidification of the re-melted zone (RZ), directional crystallization caused the copper samples modified with titanium powder to adopt a structure consisting of an $\alpha$ matrix and a separated $\mathrm{Cu}$-Ti phase. EDS testing of the re-melted zone area revealed that the mass composition was $\mathrm{Ti} 6.58 \% \mathrm{wt}$. and $\mathrm{Cu} 93.42 \% \mathrm{wt}$., which was confirmed by the intensity plot in Figure 9b. This was also verified by the scanning electron microscopy (SEM) study and distribution of the linear distribution of elements (Figure 10). There was a visible increase in mass concentration Ti from the RZ zone (point 0) to the HAZ zone (point $85 \mu \mathrm{m}$ ).

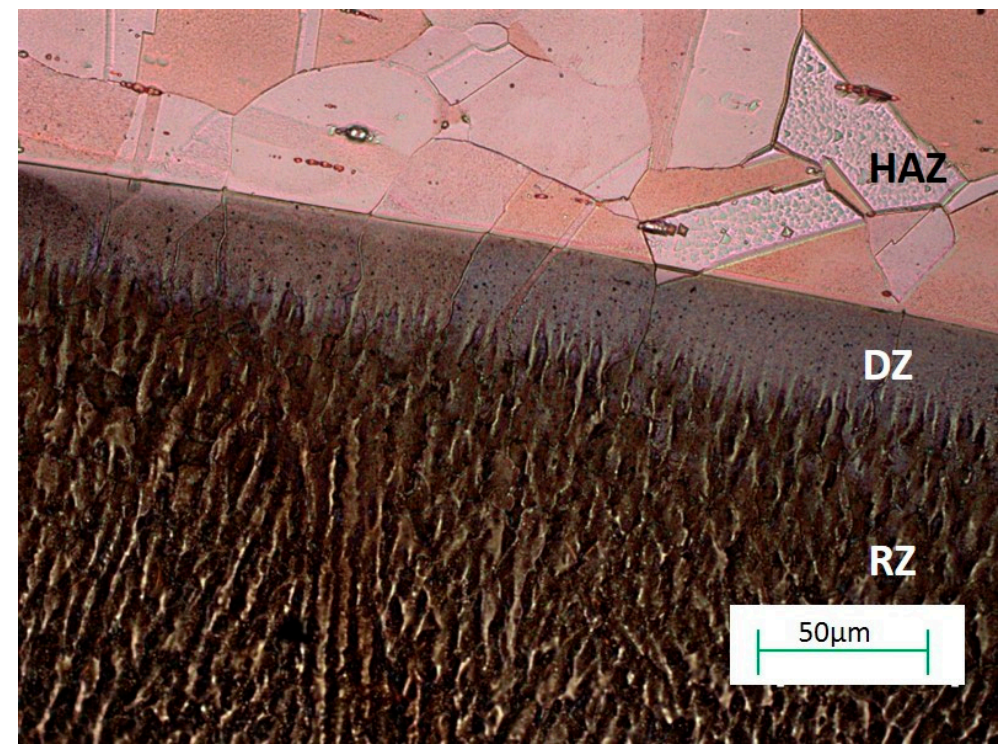

Figure 7. Optical microscopy image showing the microstructure of copper after Ti alloying.

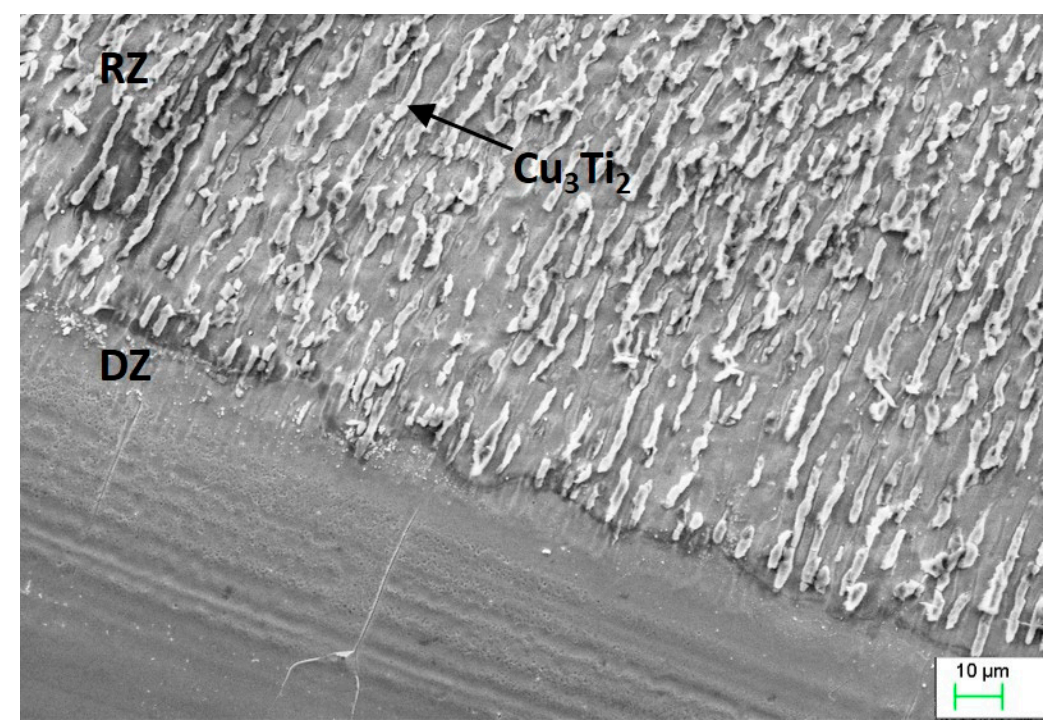

Figure 8. Scanning electron microscopy (SEM) image showing the microstructure of copper after Ti alloying. 


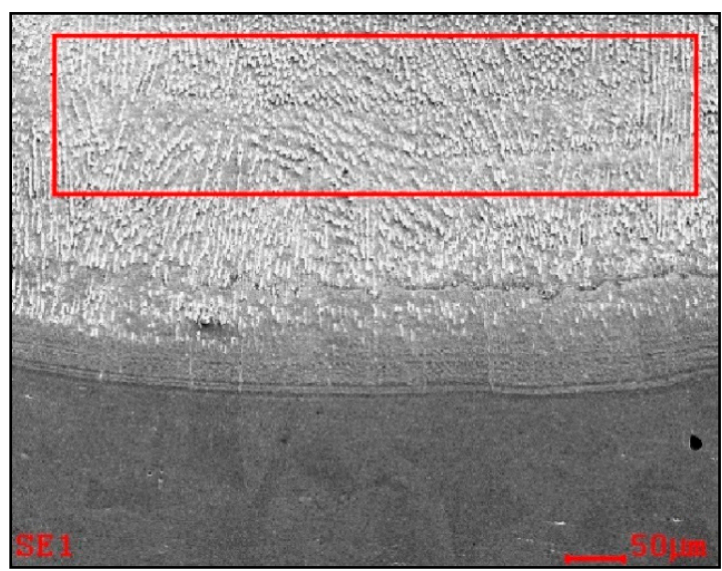

(a)

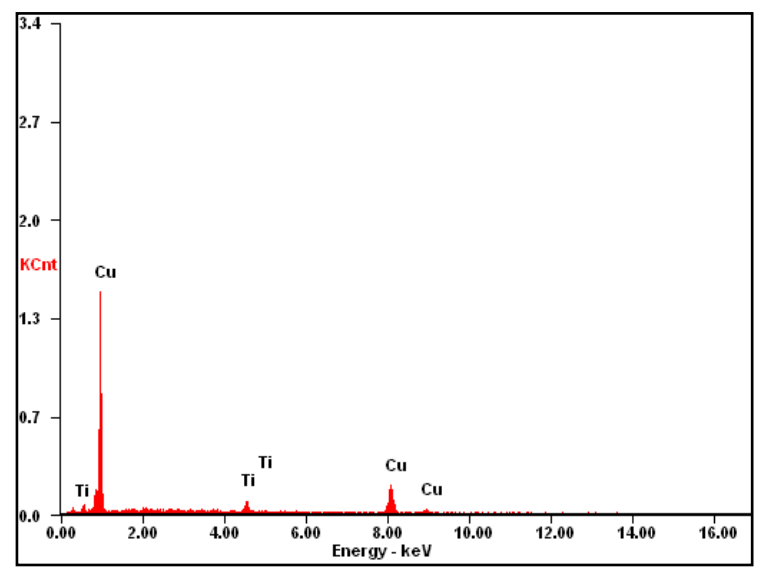

(b)

Figure 9. (a) The microstructure of the copper surface-alloyed with titanium, and (b) analysis of EDS from the selected area: $\mathrm{Ti} 6.58 \%$ wt., $\mathrm{Cu} 93.42 \%$ wt.

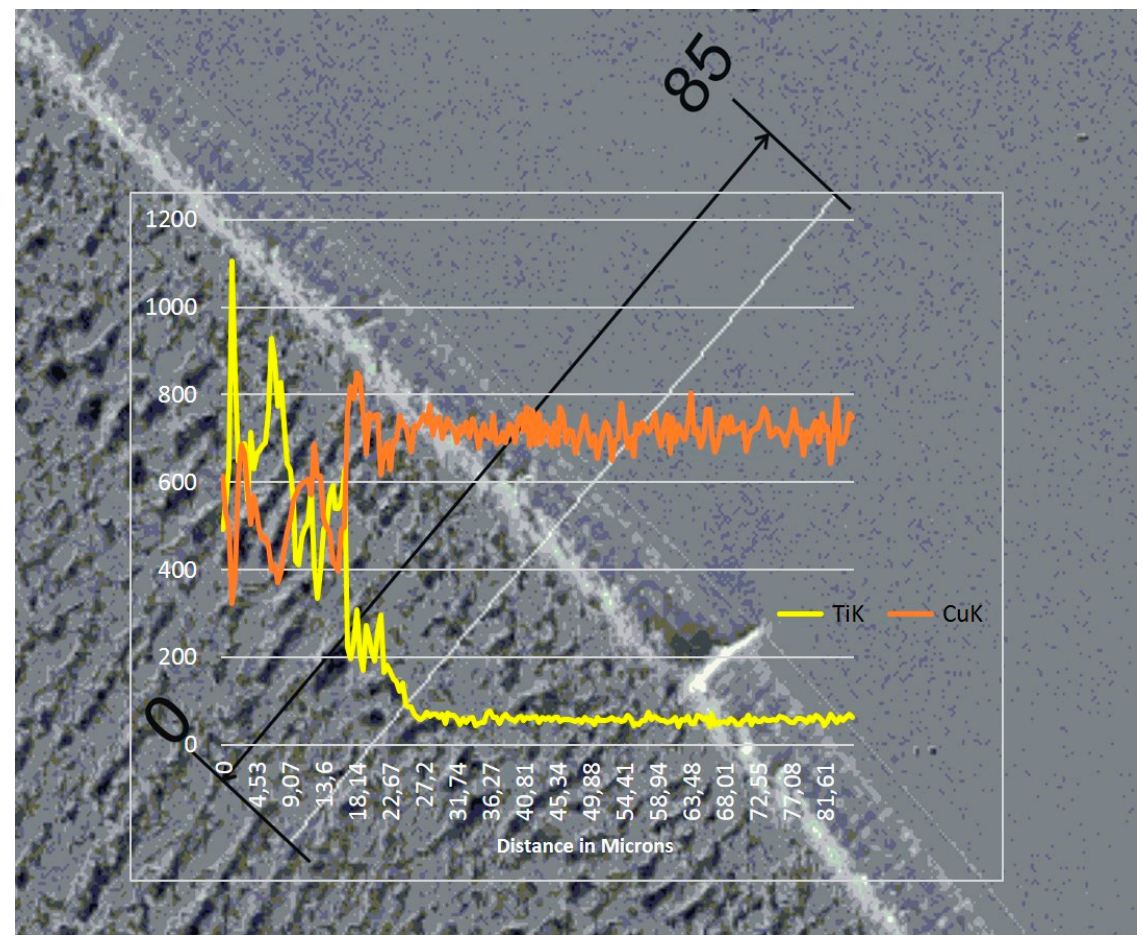

Figure 10. Linear chemical composition analysis at the zone boundary. The scale bar is $85 \mu \mathrm{m}$.

For the samples used after plastic deformation, recrystallization began with the DZ (diffusion zone) and also took place in the HAZ (heat affected zone) (Figure 11). Recrystallization went deeper into the base material to a depth of 2-3 mm, and occurred over a width slightly larger than the area of the RZ zone for the sample sizes used in this research and for the laser parameters given in Table 1 in the Materials and Methods Section.

The changes in the chemical composition and phase composition that occurred as a result of the laser modification of copper with silver and titanium powder were examined by x-ray structural analysis, and the results are presented in Figure 12. The excess of silver, which has been isolated in the $\alpha$-phase dendrite in the form of eutectics, is visible on the graph. In addition, regarding the copper substrate material after silver alloying, the diffractograms showed the presence of oxides. The notable shift of the $\mathrm{Cu}$ peak was caused by the dissolution of $\mathrm{Ag}$ in $\mathrm{Cu}$. Similarly, the change in the intensity of the $\mathrm{Cu}$ peak after alloying titanium powder was the result of the dissolution of $\mathrm{Ti}$ in $\mathrm{Cu}$ and the 
creation of the $\mathrm{Cu}_{3} \mathrm{Ti}_{2}$ phase. However, the $\mathrm{Cu}_{3} \mathrm{Ti}_{2}$ phase peak width did not exclude the formation of other $\mathrm{Cu}$-Ti phases, as confirmed by previous work [11,12,30,31]. As a result of introducing silver and titanium into copper, there was a change in the network parameter, and the calculated values are given in Table 3.

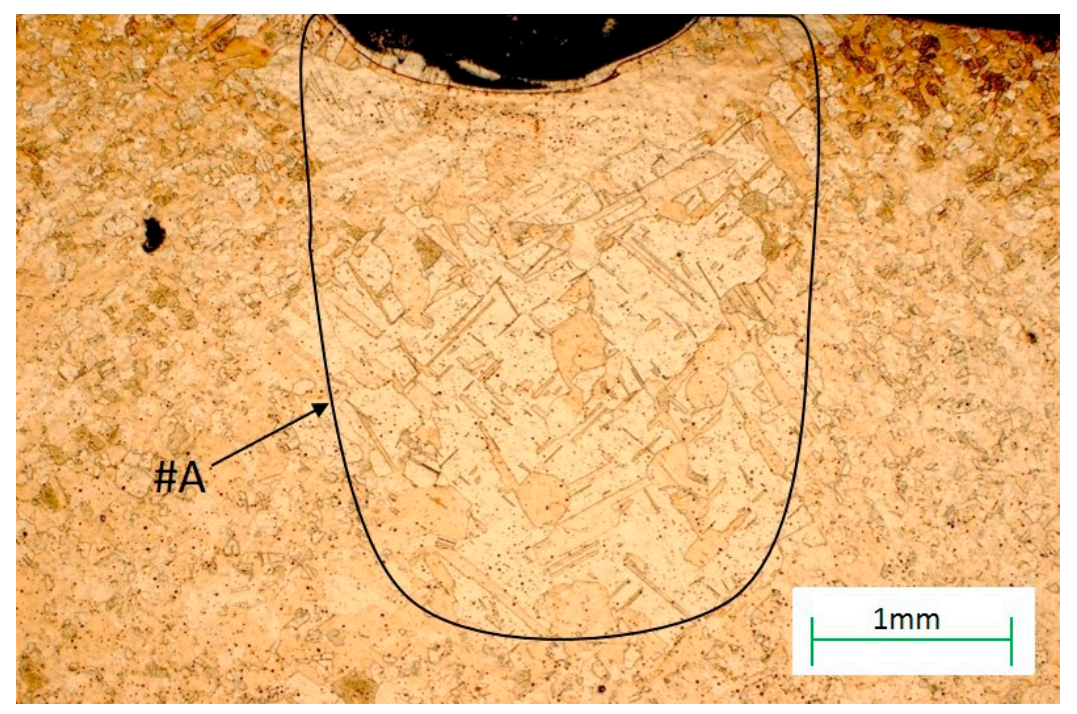

Figure 11. The microstructure of the heat affected zone (HAZ) zone with the recrystallization area, \#A, marked.

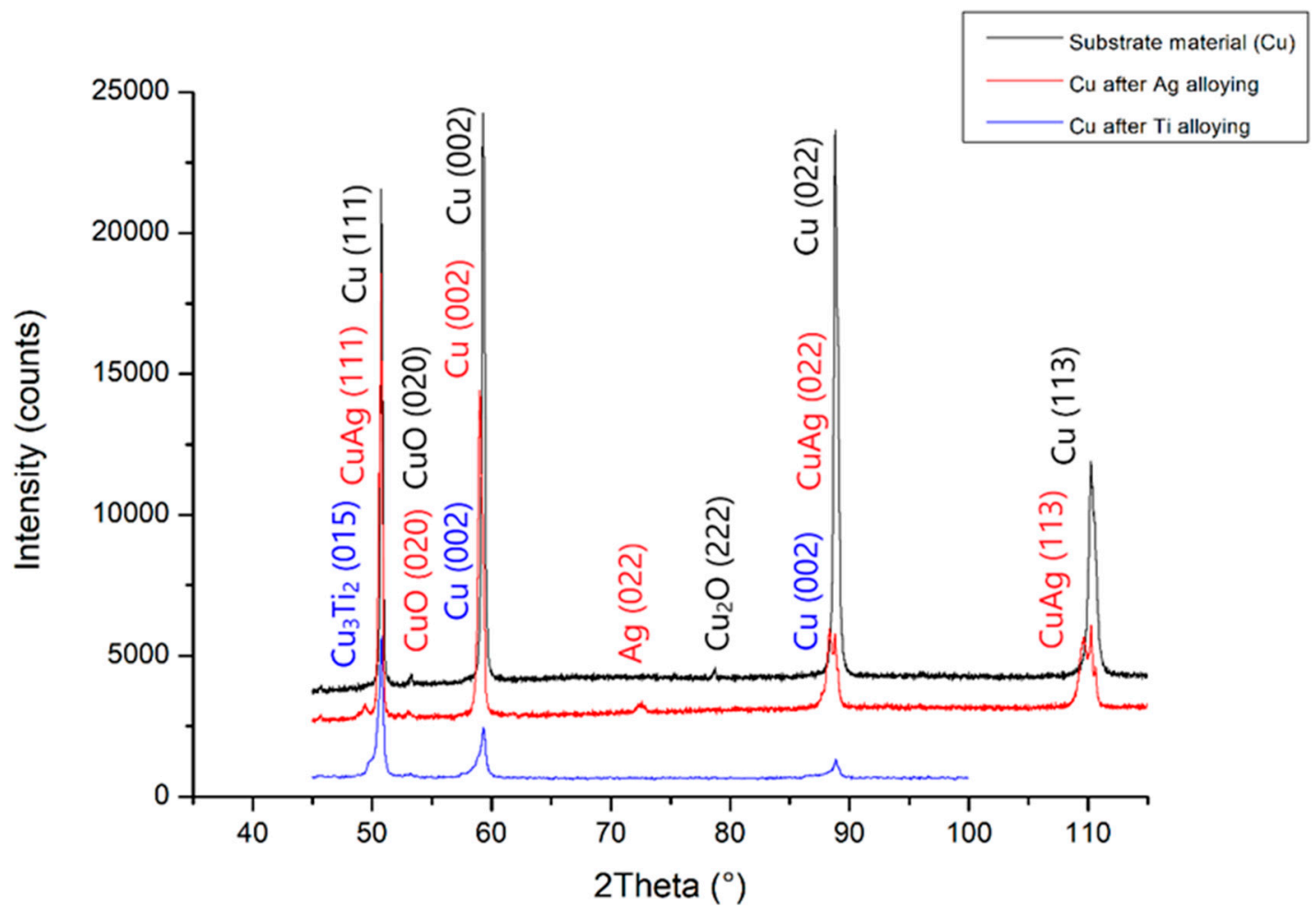

Figure 12. X-ray analysis of the substrate material before and after Ti and Ag alloying.

Table 3. Interplanar distances of the laser-alloyed copper.

\begin{tabular}{cc}
\hline The Sample & $\mathbf{d}, \AA \mathbf{A}$ \\
\hline Substrate material & 2.08746 \\
Copper after Ag alloying & 2.08712 \\
Copper after Ti alloying & 2.08690 \\
\hline
\end{tabular}


After observing the changes in the copper material's microstructure after alloying with the silver and titanium powders, hardness measurements were carried out, and the results are presented in Table 4. Compared to the copper substrate before treatment, silver powder alloying and titanium powder alloying increased the hardness by 17.2 and $356.82 \mathrm{HV}$, respectively.

Table 4. Averaged results obtained from the hardness measurements using the Vickers method.

\begin{tabular}{ccc}
\hline The Sample & Average Hardness, HV1 & Standard Deviation \\
\hline Pure copper & 112.09 & 7.65 \\
Copper after Ag alloying & 129.30 & 4.04 \\
Copper after Ti alloying & 483.37 & 2.32 \\
\hline
\end{tabular}

A ball-on-plate test was performed for the base material before and after alloying with silver and titanium powder in order to analyze how the laser modification of copper affected the surface layer properties of the material [32]. In addition, profilometer tests allowed for the calculation of the surface and volume wear of the copper material before and after alloying with the silver and titanium powders (Figures 13-15). The average abrasive surface was $683.9 \mathrm{\mu m}^{2}$ for pure copper, $595.9 \mu^{2}$ for copper alloyed with silver powder, and $360.3 \mu \mathrm{m}^{2}$ for copper alloy with titanium powder. The average volume of wear track was also calculated for copper $\left(4,103,400 \mu \mathrm{m}^{3}\right)$, copper alloyed with $\operatorname{Ag}$ powder $\left(3,575,657 \mu^{3}\right)$, and copper alloyed with Ti powder $\left(2,161,650 \mu \mathrm{m}^{3}\right)$. The presence of $\mathrm{Cu}_{3} \mathrm{Ti}_{2}$ intermetallic phases increased the abrasion resistance of the copper surface layer laser-alloyed with titanium.

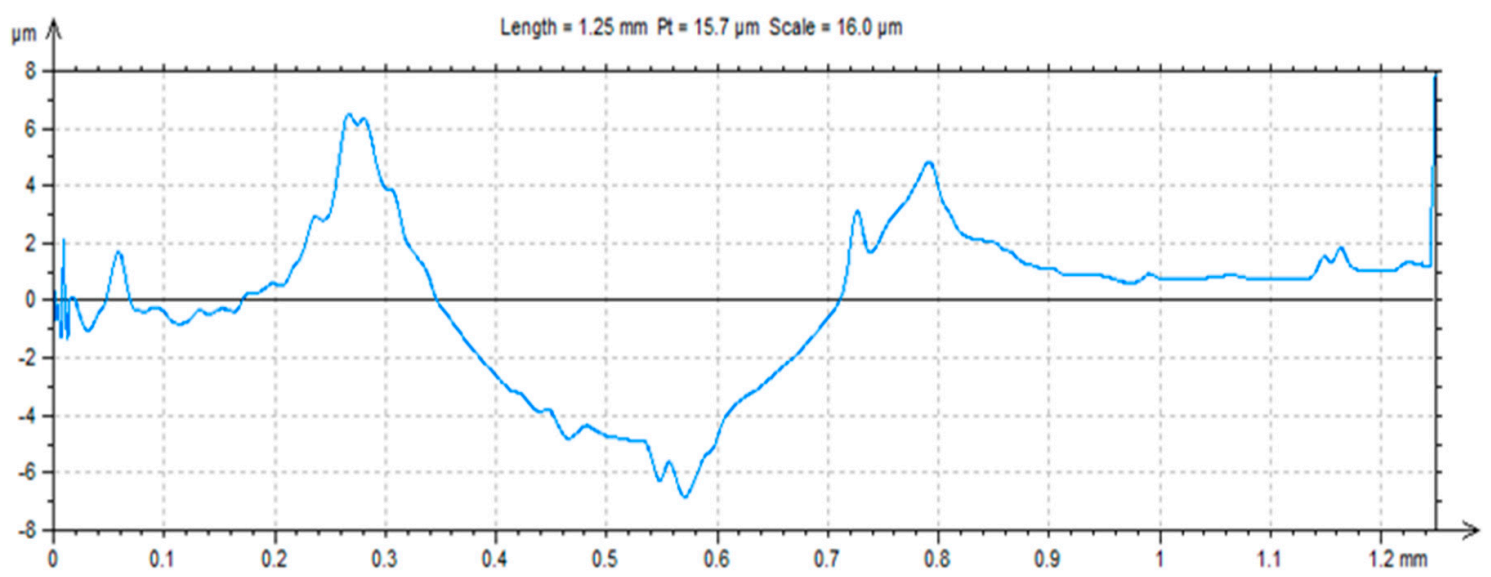

Figure 13. Trace after ball-on-plate test for pure copper.

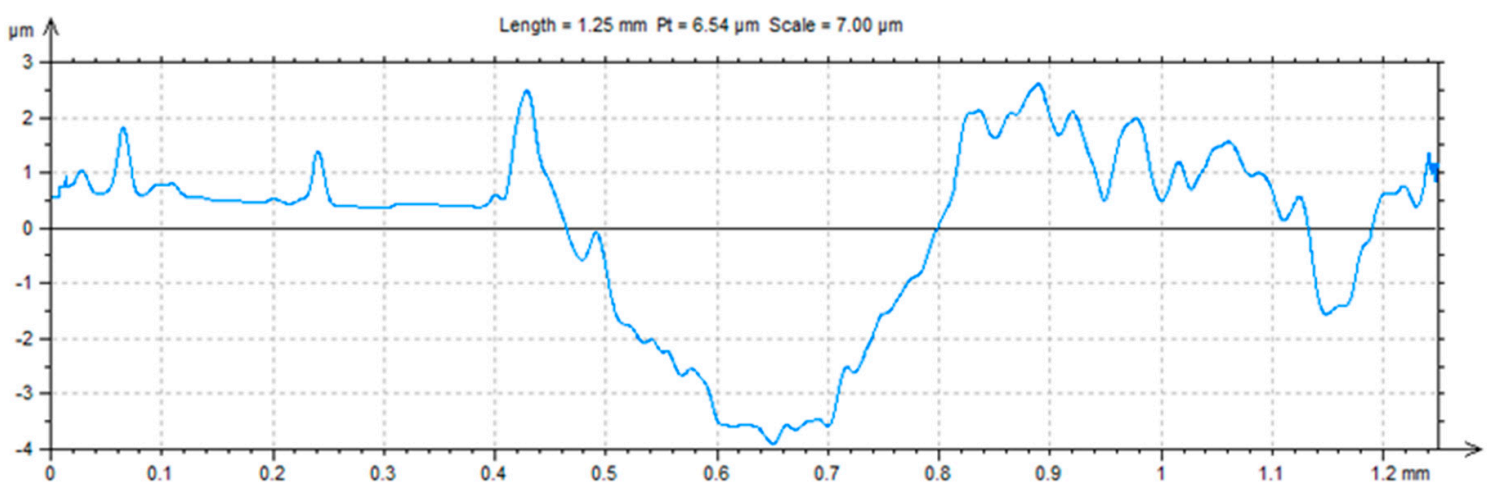

Figure 14. Trace after ball-on-plate test for material $(\mathrm{Cu})$ after $\mathrm{Ag}$ alloying. 


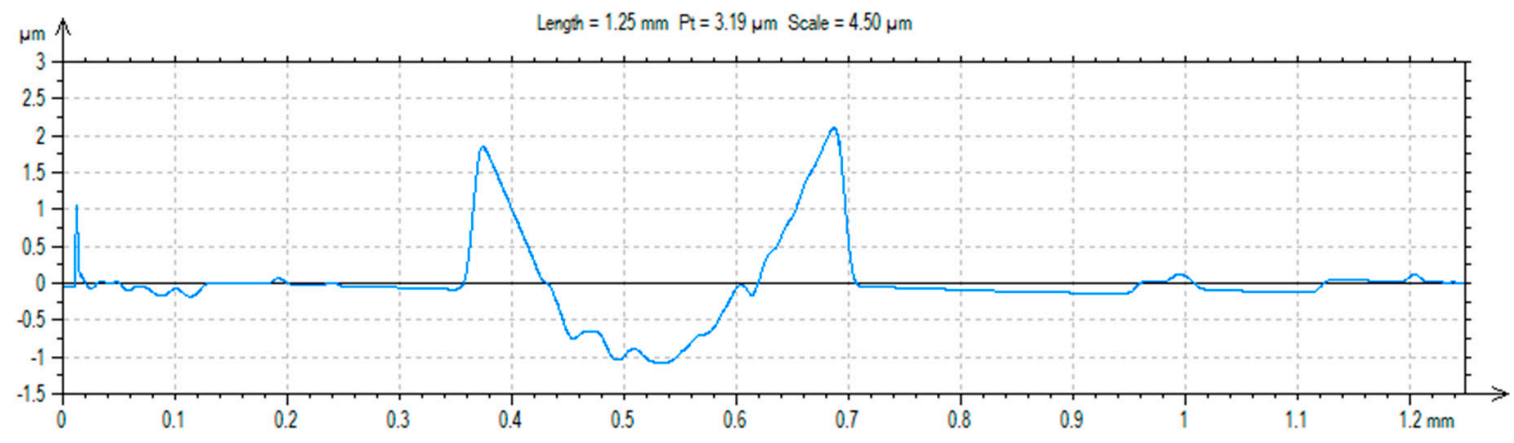

Figure 15. Trace after ball-on-plate test for material $(\mathrm{Cu})$ after Ti alloying.

The results of the conductivity test showed that the specific electrical conductivity of the material tested before the alloying process was higher than either case after treatment. The average conductivity for copper was $58.35 \mathrm{MS} / \mathrm{m}$. In the case of copper alloyed with silver powder, the material average conductivity was $42.29 \mathrm{MS} / \mathrm{m}$ (standard deviation was 0.85 ), where a decrease by $27.5 \%$ was observed.

\section{Conclusions}

Herein, we report the various impacts of laser modification of a copper surface with silver and titanium powder.

Following such a treatment, a re-melting zone (RZ), a diffusion zone (DZ), and heat affected (HAZ) zone were identified in the materials after alloying with either powder tested. The diffusion zone was created between the re-melting zone and the heat affected zone, and there was no gap between the RZ and HAZ zones because the re-melting zone solidified in the direction of the surface. Applying specific laser treatment parameters to a defined volume of the laser-processed material, the depth of the re-melting zone determined for the silver powder alloyed $\mathrm{Cu}$ was $392.67 \mu \mathrm{m}$, and for the titanium powder alloyed $\mathrm{Cu}$, it was $439.7 \mu \mathrm{m}$.

In $\mathrm{Ag}$ alloyed copper samples, some of the silver remained dissolved in the $\alpha$ matrix. As a result of segregation, excess silver crystallizes in the form of a globular eutectic $\mathrm{Cu}+\mathrm{Ag}$ (about 2-3 $\mu \mathrm{m}$ in diameter). The silver dissolved in the $\alpha$ matrix caused solid solution strengthening. Titanium powder alloying caused crystallization of the $\mathrm{Cu}_{3} \mathrm{Ti}_{2}$ phase in the direction of heat dissipation within the $\alpha$ matrix.

Overall, it was concluded that alloying the copper surface with a fiber laser leads to improvements in several strength properties. The hardness increased by $15 \%$ for the Ag case, and by $417 \%$ for the Ti case. Additionally, the material's abrasion resistance was increased, especially, as a result of the formation of intermetallic phases created after laser alloying with Ti powder. There was a decrease in the volume of wear of $53.6 \%$ in the case of the alloying of Ti powder. At the same time, conductivity decreased to $27.5 \%$.

Author Contributions: M.K. conceived and designed the experiments; M.K., P.E.S. performed the experiments; M.K., P.E.S., and M.B. analyzed the data and wrote this article. All authors have read and agreed to the published version of the manuscript.

Funding: Publication supported under the Rector's grant in the area of scientific research and development works, Silesian University of Technology, 10/010/RGJ19/0268.

Conflicts of Interest: The authors declare no conflict of interest.

\section{References}

1. Akarapu, A.; Basu, A.; Pratihar, S.K. Surface Property Modification of Copper by Nanocomposite Coating. Dep. Metall. Mater. Eng. 2011, unpublished work.

2. Przybyłowicz, K.; Skrzypek, S.J. Metals Engineering and Their Alloys; Polish Scientific Publishers PWN: Warsaw, Poland, 2012; pp. 317-343. (In Polish) 
3. Shmorgun, V.G.; Slautin, O.V.; Serov, A.G. Structure and properties of intermetallic coatings formed by laser alloying of a titanium surface with copper. Mater. Today-Proc. 2020. [CrossRef]

4. Szajnar, J.; Gawroński, J.; Roučka, J.; Šenberger, J. Modification of pure copper with sustained high electrical conductivity. Arch. Foundry 2003, 3, 241-248.

5. Krupińska, B.; Rdzawski, Z. Effect of Re addition on the crystallization, heat treatment and structure of the Cu-Ni-Si-Cr alloy. J. Therm. Anal. Calorim. 2018, 134, 173-179. [CrossRef]

6. Krupińska, B.; Rdzawski, Z.; Krupiński, M.; Pakieła, W. Precipitation Strenthening of Cu-Ni-Si Alloy. Materials 2020, 13, 1182. [CrossRef] [PubMed]

7. Andrzejewski, D.; Wendland, J.; Borowski, J.; Pachla, W. Plastic properties of semi-products made of copper by the methods of severe plastic deformation. Plast. Work. Metals 2011, 12, 153-162. (In Polish)

8. Szeftel, J.; Sandeau, N.; Khater, A. Study of the skin effect in superconduting materials. Phys. Lett. A 2017, 381, 1525-1528. [CrossRef]

9. Abdolkhani, A.B. Fundamentals of Inductively Coupled Wireless Power Transfer Systems. In Wireless Power Transfer; Coca, E., Ed.; INTECH: Christchurch, New Zealand, 2016; pp. 3-25.

10. Gambaro, S.; Valenza, F.; Passerone, A.; Cacciamani, G.; Muolo, M.L. Brazing transparent YAG to Ti6Al4V: Reactivity and characterization. J. Eur. Ceram. Soc. 2016, 36, 4185-4196. [CrossRef]

11. Gambaro, S.; Muolo, M.L.; Valenza, F.; Cacciamani, G.; Esposito, L.; Passerone, A. Wettability of transparent YAG $\left(\mathrm{Y}_{3} \mathrm{Al}_{5} \mathrm{O}_{12}\right)$ by molten Ag-Cu-Ti alloys. J. Eur. Ceram. Soc. 2015, 35, 2895-2906. [CrossRef]

12. Andrieux, J.; Dezellus, O.; Bosselet, F.; Viala, J.C. Low-Temperature Interface Reaction between Titanium and the Eutectic Silver-Copper Brazing Alloy. J. Phase Equilib. Diff. 2009, 30, 40-45. [CrossRef]

13. Semboshi, S.; Ishikuro, M.; Sato, S.; Wagatsuma, K.; Takasugi, T. Extraction of precipitates from age-hardenable $\mathrm{Cu}-\mathrm{Ti}$ alloys. Mater. Charact. 2013, 82, 23-31. [CrossRef]

14. Robinson, J.R.; Van Brussel, A.B.; De Hosson, J.T.M.; Reed, R.C. X ray measurement of residual stresses in laser melted Ti-6Al-V alloy. Mater. Sci. Eng. 1996, A208, 143-147. [CrossRef]

15. Gireń, B.G.; Szkodo, M.; Steller, J.K. The influence of residual stresses on cavitation resistance of metals-An analysis based on investigations of metals remelted by laser beam and optical discharge plasma. Wear 1999, 233, 86-92. [CrossRef]

16. Gripenberg, H.; Keinänen, H.; Ohms, C.; Hänninen, H.; Stefanescu, D.; Smith, D. Prediction and Measurement of Residual Stresses in Cladded Steel. Mater. Sci. Forum. 2010, 404, 861-866. [CrossRef]

17. Grum, J.; Znidarsic, M. Strain Measurement during Laser Surface Cladding of Low Carbon Steel and Analisis of Residual Stresses. Mater. Sci. Forum. 2002, 404, 437-444. [CrossRef]

18. Cheng, W.; Finnie, I.; Gremaud, M.; Rosselet, A.; Streit, R.D. The Compliance Method for Measurement of Near Surface Residual Stresses-Application and Validation for Surface Treatment by Laser and Shot-Peening. J. Eng. Mater.-T ASME 1994, 116, 1242-1253. [CrossRef]

19. Kwok, C.T. Laser Surface Alloying of Various Engineering Alloys for Sliding Wear and Corrosion Resistance. J. Laser Micro Nanoeng. 2010, 5, 90-96. [CrossRef]

20. Dinesh Babu, P.; Buvanashekaran, G.; Balasubramanian, K.R. Experimental investigation of laser transformation hardening of low alloy steel using response surface methodology. Int. J. Adv. Manuf. Technol. 2013, 67, 1883-1897. [CrossRef]

21. Liu, C.; Liang, J.; Zhou, J.; Wang, L.; Li, Q. Effect of laser Surface melting on microstructure and corrosion characteristics of AM60B magnesium alloy. Appl. Surf. Sci. 2015, 343, 133-140. [CrossRef]

22. Jiru, W.G.; Sankar, M.R.; Dixit, U.S. Investigation of microstructure and microhardness in laser surface alloyed aluminium with $\mathrm{TiO}_{2}$ and $\mathrm{SiC}$ powders. Mater. Today-Proc. 2017, 4, 717-724. [CrossRef]

23. Zhou, J.; Xu, J.; Huang, S.; Hu, Z.; Meng, X.; Feng, X. Effect of laser Surface melting with alternating magnetic field on wear corrosion resistance of magnesium alloy. Surf. Coat. Technol. 2017, 309, 212-219. [CrossRef]

24. Froend, M.; Ventzke, V.; Riekehr, S.; Kashaev, N.; Klusemann, B.; Enz, J. Microstructure and microhardness of wire-based laser metal deposited AA5087 using an Ytterbium fibre laser. Mater. Charact. 2018, 143, $59-67$. [CrossRef]

25. Pakieła, W.; Tański, T.; Brytan, Z.; Chladek, G.; Pakieła, K. The impact of laser surface treatment on microstructure, wear resistance and hardness of the AlMg5 aluminum alloy. Appl. Phys. A Mater.Sci. Process. 2020, 126, 1-10. [CrossRef]

26. Li, M.; Chao, M.; Liang, E.; Yu, J.; Zhang, J.; Li, D. Improving wear resistance of pure copper by laser surface modification. Appl. Surf. Sci. 2011, 258, 1599-1604. [CrossRef] 
27. Paczkowska, M.; Selech, J. An investigation of the influence of laser alloying of the surface layer on abrasive wear resistance of cast iron elements. Tribologia 2018, 6, 107-117. [CrossRef]

28. Ng, K.W.; Man, H.C.; Cheng, F.T.; Yue, T.M. Laser cladding of copper with molybdenum for wear resistance enhancement in electrical contacts. Appl. Surf. Sci. 2007, 253, 6236-6241. [CrossRef]

29. Dobrzański, L.A.; Tański, T.; Dobrzańska-Danikiewicz, A.D.; Król, M.; Malara, S.; Domagała-Dubiel, J. Structure and properties of Mg-Al-Zn alloys. Open Access Libr. 2012, 5, 11.

30. Dezellus, O.; Arroyave, R.; Fries, S.G. Thermodynamic modelling of the Ag-Cu-Ti ternary system. Int. J. Mater. Res. 2011, 102, 286-297. [CrossRef]

31. Zhao, Y.; Wang, W.; Yan, K.; Liu, C.; Zou, J. Microstructure and properties of Cu/Ti laser welded joints. J. Mater. Process. Technol. 2018, 257, 244-249. [CrossRef]

32. Kwok, C.T.; Wong, P.K.; Man, H.C. Laser Surface alloying of copper with titanium: Part I. Electrical wear resistance in dry condition. Part II. Electrical wear resistance in wet and corrosive condition. Surf. Coat. Technol. 2016, 297, 58-73. [CrossRef]

(C) 2020 by the authors. Licensee MDPI, Basel, Switzerland. This article is an open access article distributed under the terms and conditions of the Creative Commons Attribution (CC BY) license (http://creativecommons.org/licenses/by/4.0/). 